\title{
Fetal Dopaminergic Neurons Transplanted to the Normal Striatum of Neonatal or Adult Rats and to the Denervated Striatum of Adult Rats
}

\author{
${ }^{1}$ Vandana Sable, K. Sailaja, Gomathy Gopinath and P.N. Tandon ${ }^{2}$ \\ Neural Transplantation Unit, Departments of Anatomy and Neurosurgery ${ }^{2}$ \\ All India Institute of Medical Sciences, New Delhi 110029, India
}

\section{SUMMARY}

Fetal ventral mesencephalon from the 15th gestational day was grafted into the striatum of neonatal and adult rats. In one group of adult rats, fetal nigra was transplanted into normal striatum. In a second group, the tissue was transplanted at sites where dopaminergic fibers were denervated with 6-hydroxydopamine. The behavior of the dopaminergic neurons and glial reactions were studied by staining with cresyl violet to localize the transplants and by immunolabeling tyrosine hydroxylase (TH) and glial fibrillary acidic protein. In normal adults, the transplants were small. At the edge of the transplants, TH-positive neurons were packed into clusters, and an interface without any significant crossover of TH-positive fibers was present. Glial reaction was minimal in and around the transplant. In the denervated striatum, transplants were generally larger than those in normal striatum and surrounded by a glial scar. TH-positive neurons were both closely packed and loosely arranged at the periphery of the transplants. Processes could be clearly defined and could be traced to the adjacent host striatum through the TH-free denervated area. In neonates, the transplants were large and at times extended beyond the striatum. Most THpositive neurons were arranged linearly along

\footnotetext{
Correspondence address:

Dr. Vandana Sable

Department of Anatomy

AIIMS, New Delhi 110029, India

Fax: +91-11-6862663
}

the periphery of the transplant. Cell bodies were widely separated and a well-developed neuropil was present. Fibers from the transplant mingled freely with the host striatum without any interface. In all three transplant groups, tracing the TH-positive neurites was easy because they were thicker and coarser than other elements. No apparent glial reaction occurred in the neonates. Thus, the growth and maturation of dopaminergic neurons seemed to vary in different environments. The most conducive environment appears to be neonatal brain in which growth factors are readily available.

\section{KEY WORDS}

fetal nigra, transplant, denervation, neonate, tyrosine hydroxylase, glia

\section{INTRODUCTION}

Experimental animal research on the growth pattern and behavior of transplanted fetal neurons in the host brain has considerably contributed to the understanding of developmental neurobiology. Based on the observations obtained from these early investigations, subsequent animal experiments were modified to achieve the recovery of functions after lesioning of different brain regions as a prelude to using neural transplantation as an effective therapy in humans for some of the better understood neurodegenerative diseases. Many factors have been reported to influence graft survival and maturation, as well as the integration of grafted neurons with host brain and the potential to restore lost neurologic functions. Notable among such factors are the age of the donor and the host, the status and 
nature of the transplant sites, and the availability of trophic factors. Various reports are available supporting the influential role of each element on the growth and differentiation and integration of grafted neurons. The better growth pattern of neuronal processes has been reported in neonates $/ 12,17,20,21,24 /$, in lesioned host sites $/ 1,11 /$, and at the target site $/ 2,22 /$. Several studies $/ 6,18,19 /$ have dealt with the role on the survival and growth of donor tissue of neurotrophic factors (NF) that are released after lesioning the host brain. The influence of NF on the maturation and establishment of connection of the donor tissue with the target tissue is well-established from a large number of studies $15,6,18,19,29 /$. Very few investigations, however, have made a comparative study of the nature of the transplanted neurons under various conditions. Das et al. /8/ published the only report of a comparative morphological evaluation of transplants that were obtained from donor embryo tissues of different ages.

Some interesting observations of nigral transplants in neonatal and adult rats, with or without lesion, are compiled in the present article.

\section{MATERIALS AND METHODS}

\section{Experimental animals}

Stock-bred Wistar rats obtained from AIIMS Central Animal Facility were used for this study. The animals were housed in a room with an ambient temperature between $22-24{ }^{\circ} \mathrm{C}$ and a light-dark cycle of $12 \mathrm{hr}$ each. One-day-old (the day after birth) rat pups were used as neonatal host, and three mo-old rats weighing 150-200 gm each were used as adult hosts. The adult rats were housed individually, whereas the pups were left with the mother. Food and water were allowed ad libitum.

\section{Striatal denervation}

Dopaminergic fibers in the striatum on the left side were denervated by injecting 6-hydroxydopamine (6-OHDA, Sigma Chemical Co., St. Louis, MO, USA) at two sites. Rats were anesthetized by intramuscular injection of ketamine hydrochloride $(40 \mathrm{mg} / \mathrm{kg}$ body weight) and fixed in a stereotaxic apparatus. For injecting the 6-OHDA, two sets of stereotaxic coordinates were selected: (i) AP+8.6, L2.5, and V-1.2; and(ii) AP+7.4, L3.0, and V-1.5. Each animal received a total of $8 \mu \mathrm{g}$ 6-OHDA ( $4 \mu \mathrm{g}$ per site), dissolved in $4 \mu \mathrm{L}$ of ascorbic acid ( $0.2 \%$ in normal saline). Seven days later, the treated animals were used for transplantation experiments.

\section{Donor tissue}

Adult male and female rats were paired in cages, and the sperm positivity in vaginal smears was determined the next morning. The day of sperm positivity was taken as the zero day of pregnancy. Sperm-positive females were isolated in individual cages. On the 15th gestational day, the pregnant rats were anesthetized by ketamine hydrochloride, the abdomen was opened, and from each uterine horn one fetus at a time was removed. Meninges and blood vessels were removed from the mesencephalon region, and the ventral part was sliced out and collected in a petri dish containing a chilled Ringer's lactate solution. The tissue was triturated by passing it repeatedly through a glass needle, and the fine bits were suspended in a small volume of the same solution. After all the fetuses had been removed, the mother was sacrificed by a lethal dose of ketamine hydrochloride.

\section{Neonatal transplantation}

Rat pups were anesthetized by hypothermia. Coordinates for striatal tissue injection of donor tissue were $1.0 \mathrm{~mm}$ anterior to bregma, $2.0 \mathrm{~mm}$ lateral to midline, and $2.0 \mathrm{~mm}$ deep to the skull surface. Donor tissue was taken in a glass capillary needle attached to a $1 \mathrm{~mL}$ tuberculin syringe, and the needle was introduced through a hole made by a sterile needle in the cartilaginous skull. An aliquot (3-5 $\mu \mathrm{L})$ of donor tissue was injected very slowly over $2 \mathrm{~min}$, and the needle was retained for $2 \mathrm{~min}$ longer to prevent reflux of the donor tissue. The pups were warmed to normal temperature before they were returned to the mothers.

\section{Adult transplantation}

Seven days after unilateral lesion, adult rats were anesthetized, and an aliquot $(5-8 \mu \mathrm{L})$ of donor 
tissue was injected at one of the 6-OHDA injection sites. In adult rats without striatal denervation, the coordinates used for transplantation were $\mathrm{AP}+8.6$, L2.5, and V-1.2.

\section{Tissue collection and processing}

Rats were sacrificed at regular 10-day intervals. On each day, a minimum of six transplants were obtained for the study. The observations reported here apply to the 30th post-transplantation day, but are generally applicable to the later experimental days as well. The rats were deeply anesthetized with ketamine hydrochloride before perfusion with cold $0.1 \mathrm{M}$ phosphate buffer ( $\mathrm{pH}$ 7.4) followed by periodate-lysine-paraformaldehyde fixative $/ 16 /$. The brains were removed and were postfixed for another $24 \mathrm{hr}$ at $4{ }^{\circ} \mathrm{C}$ in the same fixative. The transplant area was removed by coronal cuts and then transferred to graded concentrations of sucrose $(15 \%, 20 \%, 30 \%)$ in phosphate buffer. Serial cryosections, $7 \mu \mathrm{m}$ thick, were cut coronally and were collected on subbed slides. A few slides chosen at random were stained with cresyl violet to localize the transplant. Sections adjacent to the transplant were used for immunohistochemical staining of tyrosine hydroxylase (TH) and glial fibrillary acidic protein (GFAP), using commercial monoclonal antibodies (GMbH, Boehringer Mannheim, Germany). Before the immunolabeling, the sections were treated with hydrogen peroxide (4\% in methanol) to suppress endogenous peroxidase activity. The sections were rinsed thrice in $0.1 \mathrm{M}$ phosphate buffered saline adjusted to $\mathrm{pH} 7.4$ (PBS) and then incubated for $30 \mathrm{~min}$ in 10\% normal horse serum (NHS), followed by overnight incubation at $4{ }^{\circ} \mathrm{C}$ with a primary antibody against either $\mathrm{TH}$ or GFAP diluted 1:500 in PBS containing $8 \%$ NHS AND $0.3 \%$ Triton $X$. The sections were rinsed thrice in PBS and processed using an avidin-biotin method (Vectastain ABC Elite Kit, Vector Laboratories), with hydrogen peroxide $(0.03 \%$ in PBS) as substrate and 0.6\% 3,3-diaminobenzedine as chromogen. The sections were dehydrated and mounted in DPX, and the slides were examined and photographed.

\section{RESULTS}

The following observations were made on the 30th post-transplantation day in normal neonatal, normal adult, and denervated adult hosts. In sections stained with cresyl violet, transplants could be clearly identified in both groups of adult rats by the characteristic cytoarchitecture of the surrounding host. Generally the size of the transplants in the denervated sites were larger than those in the normal striatum, although the size and shape of the transplants varied considerably. The transplants in the neonates had assumed a much larger size. The drawings in Figs. 1-3 show the representative sizes of the transplants in the different groups.

Grafted neurons in normal striatum showed a tendency to crowd into clusters at the host-graft interface and appeared as densely stained THpositive patches. Cluster size varied in different transplants. The cell bodies of TH-positive neurons measured between 10-20 $\mu \mathrm{m}$. Immunoreactive fibers, thicker and coarser than those in the host striatum, were restricted to the dense immunoreactive patches. Only a very small number of immunoreactive fibers could be seen in the remaining areas of the transplant. A few fibers could be traced into the interface between the graft and the host (Fig. 4). In the normal adult, glial cells in and around the transplants appeared to be only mildly reactive to the anti-GFAP antibody.

The tendency of TH-positive neurons to migrate close to the host striatum was also observed in denervated striatum. Along with small clusters of compactly arranged neurons, loosely arranged immunoreactive neurons with radiating fibers were present as well. Individual fibers could be traced into the host striatum through the denervated host area, which at times were recognizable by negligible immunoreactivity between the transplant and the immunoreactive part of the host striatum. The size of the TH-positive neurons in this group measured between 7.5-30 $\mu \mathrm{m}$ and the length of the processes ranged from $60-100 \mu \mathrm{m}$ (Figs. 5, 7). From the 30th post-transplantation day onward, a clear-cut glial scar forming a boundary was visible in relation to all neural transplants in denervated striatum. The astrocytes in the transplant were less reactive than the astroglia in the neighboring host brain (Fig. 9). 

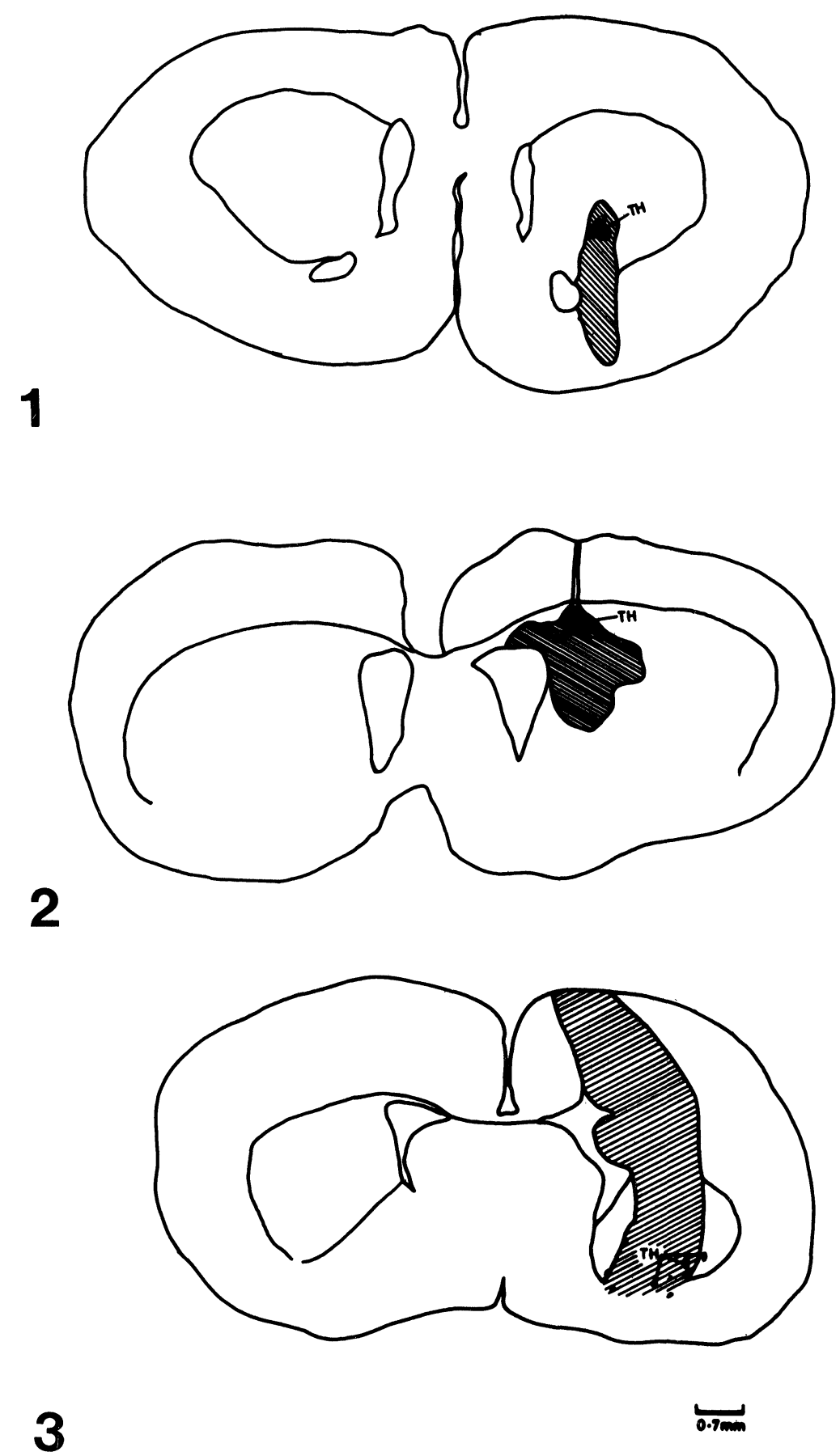

Figs. 1-3. Coronal sections of the brain through the striatum showing transplants (striped area) and the distribution of dopaminergic neurons (shaded, TH) in (1) normal adult, (2) denervated adult, and (3) neonatal rat striatum. 

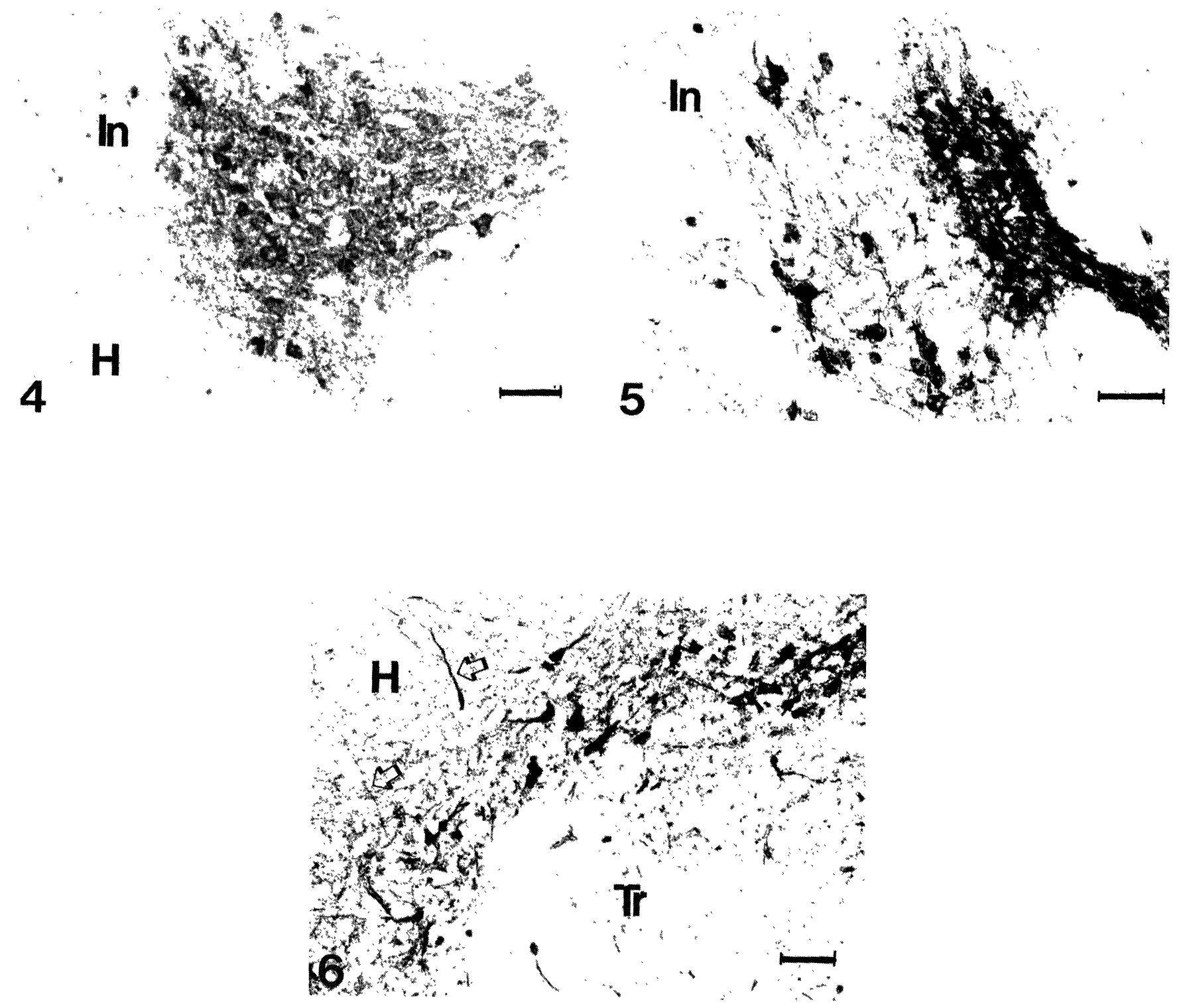

Fig. 4. Normal adult striatum: Transplant showing compactly arranged TH-positive neurons and fibers. Individual fibers are not clearly seen. Fine TH fibers of the host $(\mathrm{H})$ and the interface (In) between the host striatum and the transplant are also seen Bar - $50 \mu \mathrm{m}$.

Fig. 5. Denervated adult striatum: Transplant with TH-positive neurons and fibers. Densely positive area with clustering of immunoreactive neurons and fibers and an area with loosely arranged neurons and fibers are seen. Fibers with comparatively less reactivity for TH cross the interface (In). (Magnified view shown in Fig. 7). Bar - $50 \mu \mathrm{m}$.

Fig. 6. Neonate: Part of a transplant with TH-positive neurons and fibers distributed at the periphery, juxtaposed to the host $(\mathrm{H})$ striatum. Fibers are seen crossing over to the host striatum (arrow heads). The transplant is integrated with the host brain without any interface region. Bar $-50 \mu \mathrm{m}$. (Magnified view shown in Fig. 8) 

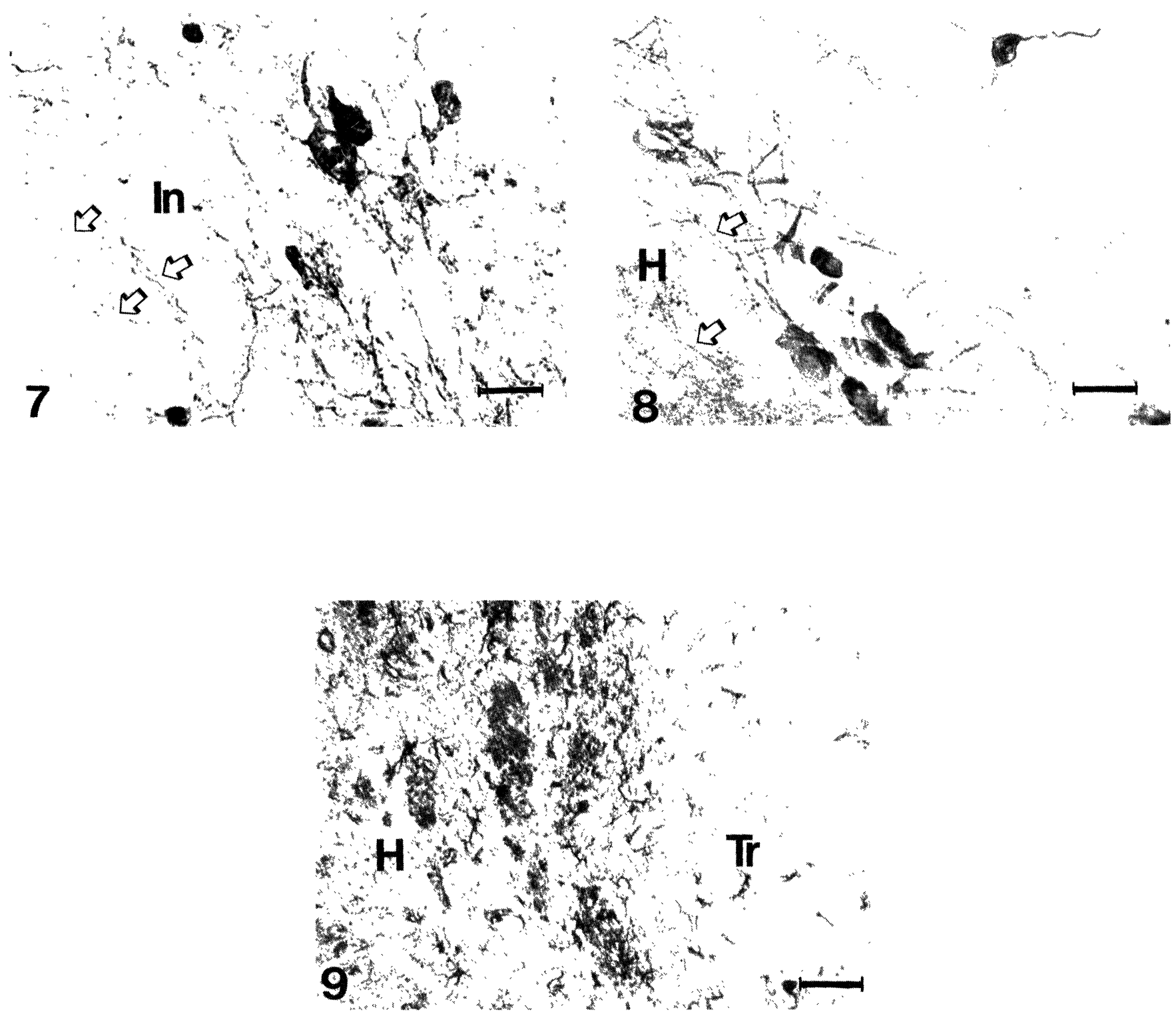

Fig. 7. Denervated adult striatum: Magnified view of Fig. 5 showing loosely arranged TH-positive neurons and fibers. Thicker and coarser fibers from the transplant (arrow heads) can be seen crossing over to the host striatum through an interface zone (In) with comparatively less TH-reactivity. Bar $-25 \mu \mathrm{m}$.

Fig. 8. Neonate: Magnified view of Fig. 6. Note the fine TH-positive fibers in the host $(\mathrm{H})$ striatum compared with the thicker and coarser fibers (arrow heads) of the transplanted TH-positive neurons. An isolated TH-positive neuron with radiating fibers is seen inside the transplant, well away from the periphery. Note the paucity of TH-positive fibers in this region as compared to the peripheral part. Bar $-25 \mu \mathrm{m}$.

Fig. 9. Denervated adult striatum: Part of a glial barrier demonstrated by GFAP-immunopositivity (arrow heads) between transplanted $(\mathrm{Tr})$ and host $(\mathrm{H})$ striatum. Immunopositive astroglia are seen in both host and transplant. Bar $-25 \mu \mathrm{m}$. 
In the neonates, the transplants were large and extended into the adjacent areas. Demarcating the transplant from the surrounding host brain was not easy. The absence of a distinct interface between graft and host tissue, as well as the presence of THpositive neurons in the adjacent host striatum suggested the integration of host and grafted neural tissues. Immunoreactive neurons arranged along the periphery of the transplant formed a clear landmark in all neonatal transplants. The neuropil between the neurons was well formed, and immunoreactive fibers could be traced into the host striatum. The neuronal diameter ranged from $10-30 \mu \mathrm{m}$, and the length of the fibers ranged from 75-130 $\mu \mathrm{m}$. Isolated immunoreactive neurons were also encountered elsewhere in the transplant. Neurites were seen radiating from the cell bodies (Figs. 6,8).

That the immunoreactive fibers from the transplanted neurons were thicker and coarser than those of the dopaminergic fibers of the host striatum facilitated the identification and measurement of the fibers in all three groups.

\section{DISCUSSION}

That the status of the host tissue at the time of transplantation plays an important role in the pattern of growth, maturation, and distribution of the grafted neurons is evident not only from the results of our present study but also from the observations reported in other studies $/ 23,25 /$. Our observations in the normal adult host agree with reports showing restricted neurite outgrowth $/ 14 /$ and limited penetration of the fibers into the host brain $/ 7 /$. In adult rats, the smaller size of the grafts and the aggregation of TH-positive neurons in clusters appeared to be due to the resistance offered by the compact and unyielding nature of the mature host striatum. Similar observations have been made by Snyder-Keller et al. $/ 26 /$, who suggested that the environment in the intact host striatum is less conducive to the maturation and fiber growth of embryonic neurons because target sites and trophic factors are absent. Despite the compact nature of the adult striatum, the absence of target sites and trophic factors, it is noteworthy that the dopaminergic neurons of the donor tissue migrated to the edge of the transplant to be in the proximity of the host target neurons.

Although the distribution of the dopaminergic neurons relative to host tissue appeared to be the same in both denervated and normal striatum, many grafted neurons were not in clusters in the denervated host as seen in the normal host. That thick and coarse fibers from the transplant could be traced, despite a well-formed glial scar, to the host striatum through the TH-fiber-free zone confirmed that denervation provided a more conducive environment for growth and innervation of the target tissue. Besides providing contact sites on the target neurons $/ 3 /$, injury reportedly also releases trophic factors that influence the survival and fiber outgrowth of grafts in lesioned rats $/ 6,18,19 /$. Chemical lesioning has also been reported to produce trophic effects in directing fiber outgrowth 130/. According to Doucet et al. /10/, additional factors other than those produced by tissue damage could be produced that may favor connectivity between host and graft.

The large size of the transplant in neonatal hosts clearly shows the influence of the age of the recipient on the ultimate size of the transplant, as shown by Hallas et al. /12/. Stenevi et al. /27/ and Hallas et al. /12/ reported that fetal cells develop best when transplanted to neonatal host brain. Das 19/ perceived that the pliable nature and large intercellular space in the neonatal brain, as described by Vernadakis and Woodberry $/ 28 /$, favor better growth and dispersal of the grafted neurons. Better growth and integration of a graft in the neonate are also attributed to the presence of trophic factors and growth-promoting molecules in the maturing brain at the time of transplantation $/ 17 /$. Neural cell-adhesion molecules, which play an important role in the migration and maturation of neurons and the fasciculation of developing fibers, are present in the neonatal brain until postnatal day 15 but not in adult rats $/ 4,15 /$. The presence of adhesion molecules and other growth factors in the maturing brain of neonatal hosts /13/ could have promoted the better growth of neurites and the migration of the grafted embryonic neurons seen in the present study.

Other features that distinguish transplants in neonates from those in the adult are the absence of any clear interface between graft and host brain and a significant glial reaction. Plasticity of the 
immature brain undergoing development and maturation and synaptogenesis seems to favor the integration of the maturing donor tissue /24/. Nigral neurons in the target tissue must also be competing for the synaptic sites on the maturing host neurons.

Neonatal brain appears to provide the ideal environment for the growth, maturation, and integration of grafted neurons, particularly when they are transplanted close to the target site. The absence of any glial reaction and the migration of the grafted neurons into the host brain support the view that the donor tissue is accepted as native tissue.

We recently reported /15/ that the neural celladhesion molecules, NCAM and L1, are expressed even beyond the 60th post-transplantation day by the grafted mesencephalic neurons in the striatum of adult rats, whereas in normally developing rat nigra, these molecules are expressed only until the 15 th to 20 th postnatal days. The protracted expression by the grafted neurons of growth-promoting molecules in the adult host brain suggests the immature nature of such neurons, which could be due to limited or absent connections with the target neurons. Trophic factors as well as vacant contact sites on the target neurons, reportedly produced by denervation, seem to be insufficient for the better growth and integration of the grafted neurons. Our preliminary observations on the persistence of growthpromoting molecules in transplanted neurons in denervated striatum support this assumption.

It is noteworthy that in all three conditions, dopaminergic neurons migrated close to the target site, although their distribution patterns differed. Obviously certain attractants from the host target tissue are available to the immature neurons of the donor tissue and influence such close proximity.

\section{CONCLUSION}

The growth and maturation of fetal dopaminergic neurons in the target tissue differed according to the local environment. Neonatal target tissue with growth-promoting molecules and trophic factors promoted better growth and integration of donor tissue, whereas growth and maturation of grafted neurons were limited in adult target tissue, despite denervation that provided trophic factors.

\section{ACKNOWLEDGMENT}

This work is part of a project funded by the Department of Biotechnology, Government of India.

\section{REFERENCES}

1. Bjorklund A, Dunnett SB, Stenevi U, Lewis M, Iversen $\mathrm{SD}$. Reinnervation of the denervated striatum by substantia nigra transplants: Functional consequences as revealed by pharmacological and sensorimotor testing. Brain Res 1980; 199: 307-333.

2. Bjorklund A, Stenevi U, Schmidt RH, Dunnett SB, Gage FH. Intracerebral grafting of neuronal cell suspensions. II. Survival and growth of nigral cell suspensions implanted in different brain sites. Acta Physiol Scand (Suppl) 1983; 522: 9-18.

3. Carder RK, Jackson D., Morris HJ, Lund RD, Zigmond MJ. Dopamine release from mesencephalic tranplants restores modulation of striatal acetylcholine release after neonatal 6-hydroxydopamine: An in vitro analysis. Exp Neurol 1989; 105: 251-259.

4. Choung CM, Edelman GM. Alterations in neural cell adhesion molecules during development of different regions of the nervous system. J Neurosci 1984; 4: 2354-2368.

5. Coolier TJ. Neural graft augmentation through cografting of cells as sources of important molecules: Studies in animal models of Parkinson's disease. In: Marwah J, Teitelbaum H, Prasad KN, eds, Neural Transplantation, CNS Neuronal Injury, and Degeneration. Recent Advances. London: CRC Press, 1993; 39-46.

6. Cotman $\mathrm{CW}$, Nieto-Sampedro $\mathrm{M}$, Whittemore SR. Relationships between neurotrophic factors and transplant-host integration. In: Bjorklund A, Stenevi U, eds, Neural Grafting in the Mammalian CNS. New York: Elsevier Science Publishers, 1985; 169-178.

7. Crutcher KA. Age-related dcecrease in sympathetic sprouting is primarily due to decreased target receptivity: Implications for understanding brain ageing. Neurobiol-Ageing 1990; 38: 427-436.

8. Das GD, Hallas BH, Das KG. Transplantation of brain tissue in the brain of rat. I. Growth characteristics of neocortical transplants from embryos of different ages. Amer J Anat 1980; 158: 135-145.

9. Das GD, Neural transplantation in mammalian brain: Some conceptual and technical considerations. In: Wallace RB, Das GD, eds, Neural Tissue Transplantation Research, New York: Springer-Verlag, 1983; 164. 
10. Doucet G, Murata Y, Brundin P, Boster O, Mons N, Geffard $\mathrm{M}$, et al. Host afferents into intrastriatal transplants of fetal ventral mesencephalon. Exp Neurol 1989; 106: 1-19.

11. Dunnett SB, Hernandez TD, Summerfield A, Jones G H, Asbuthnott G. Graft-derived recovery from 6-OHDA lesions: Specificity of ventral mesencephalic graft tissues. Expl Brain Res 1988; 71: 411-421.

12. Hallas BH, Das GD, Das KG. Transplant of brain tissue in the brain of rat. II. Growth characteristics of neocortical transplants in hosts of different ages. Amer J Anat 1980; 158: 147-159.

13. Herman JP, Abrous DN, Le Moal M. Anatomical and behavioral comparison of unilateral dopamine-rich grafts implanted into the striatum of neonatal and adult rats. Neuroscience 1991; 40: 465-475.

14. Gage F, Bjorklund A, Senevi U, Dunnett SB. Intracerebral grafting of neuronal cell suspensions. VII. Survival and growth of implants of nigral and septal cell suspensions in intact brain of aged rats. Acta Physiol Scand (Suppl) 1983; 522: 67-75.

15. Gopinath G, Sable V, Sailaja K, Tandon PN. Cell surface molecules (NCAM and L1) in intrastriatal transplants of embryonic mesencephalon in rats. Neuroscience 1996; 73: 161-169.

16. McLean IW, Nakane PK. Periodate-Lysine-Paraformaldehyde. A new fixative for immunoelectron microscopy. J Histochem Cytochem 1974; 22: 1077-1083.

17. McLoon SC, McLoon LK. Transplantation of the developing mammalian system. In: Sladek JR, Gash DM, eds, Neural Transplants. Development and Function. New York: Plenum Press 1984; 99-124.

18. Nieto-Sampedro $M$, Whittemore $S R$, Needels $D L$, Larson JL, Cotman CW. The survival of brain transplants is enhanced by extracts from injured brain. Proc Natl Acad Sci 1984; 81: 6250-6254.

19. Nieto-Sampedro M, Lewis ER, Cotman CW, Manthorpe M, Skaper SD, Barbin GR, et al. Brain injury causes a time-dependent increase in neuronotrophic activity in the lesion site. Science 1982; 217: 860 861.

20. Nikkah G, Cunningham MG, McKay R, Bjorklund A. Dopaminergic microtransplants into the substantia nigra of neonatal rats with bilateral 6-OHDA lesions.
II. Transplant-induced behavioural recovery. J Neurosci 1995 ; 15: 3562-3570.

21. Oblinger MM, Das GD. Connectivity of transplants in the cerebellum: A model of developmental differences in neuroplasticity. In: Wallace RB, Das GD, eds, Neural Tissue Transplantation Research. New York: Springer-Verlag 1983; 105-134.

22. Olson N, Nikkah G, Bentlage C, Bjorklund A. Forelimb akinesia in the rat Parkinson modes: Differential effects of the dopamine agonists and nigral transplants as assessed by a new stepping test. J Neurosci 1995; 15: 3863-3875.

23. Rioux L, Gaudin DP, Bul LK, Gregoire L, DiPaole T, Bedard PJ. Correlation of functional recovery after a 6-hydroxydopamine lesion with survival of grafted fetal neurons and release of dopamine in the striatum of the rat. Neuroscience 1991; 40: 123-131.

24. Rogers DC, Dunnett SB. Neonatal dopamine-rich grafts and 6-OHDA lesions independently provide partial protection from the adult nigrostriatal lesion syndrome. Behav Brain Res 1989; 34: 131-146.

25. Schwarz SS, Freed WJ. Brain tissue transplantation in neonatal rats prevents a lesion-induced syndrome of adipsia, aphasia and akinesia. Exp Brain Res 1987; 65: 449-454.

26. Snyder-Keller AM, Carder RK, Lund RD. Development of dopamine innervation and turning behavior in dopamine-depleted infant rats receiving unilateral nigral transplants. Neuroscience 1989; 30: 779-794.

27. Stenevi U, Bjorklund A, Svengaard N. Transplantation of central and peripheral monoamine neurons in the adult rat brain: Techniques and conditions for survival. Brain Res 1976; 114: 1-20.

28. Vernadakis A, Woodbury M. Cellular and extracellular spaces in developing rat brain. Arch Neurol Chicago 1965; 12: 284-293.

29. Whittemore SR, Nietod-Sampedro $M$, Needels DL, Cotman CW. Neurotrophic factors for mammalian brain neurons: Injury indiction in neonatal, adult, and aged rat brain. Develop Brain Res 1985; 20: 169-178.

30. Zhou FC, Chiang YH. Excitochemical-induced trophic bridging directs axonal growth of transplanted neurons to distal target. Cell Transplant 1995; 4: 103-112. 

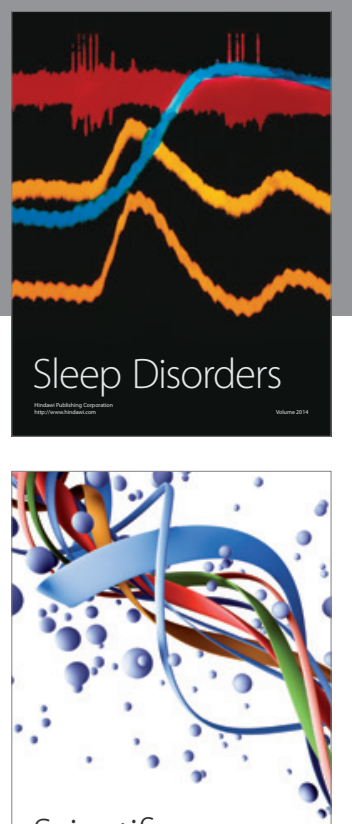

Scientifica
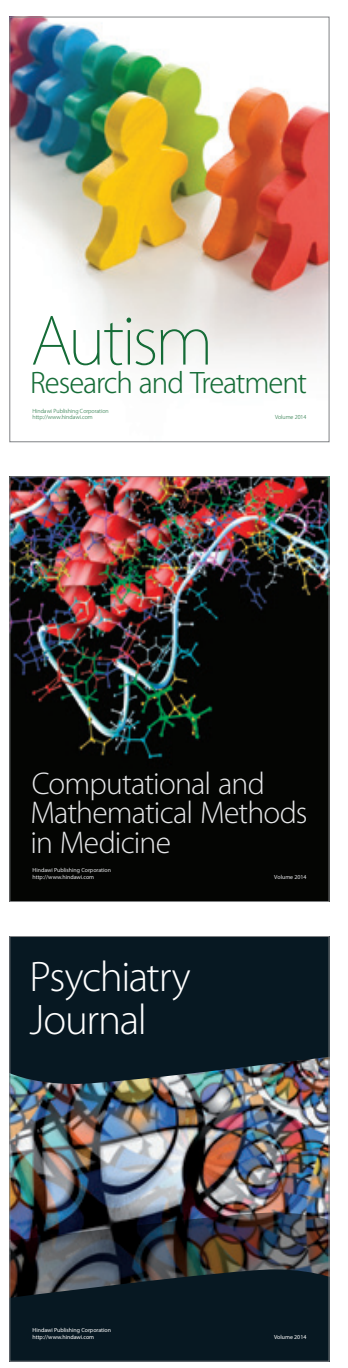
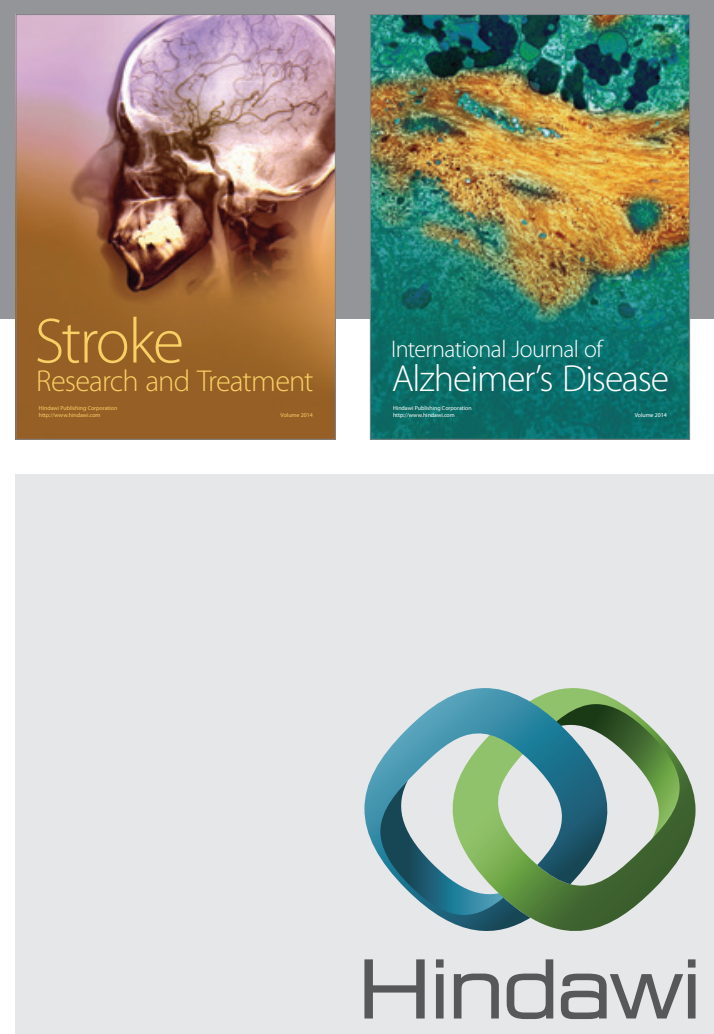

Submit your manuscripts at

http://www.hindawi.com
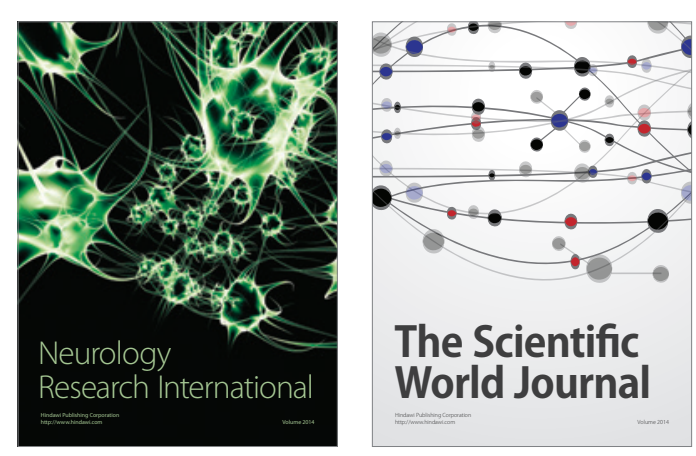

The Scientific World Journal

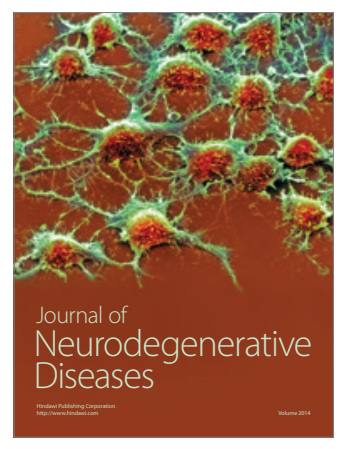

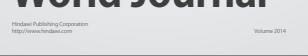

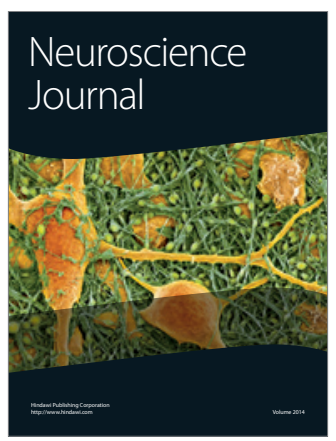

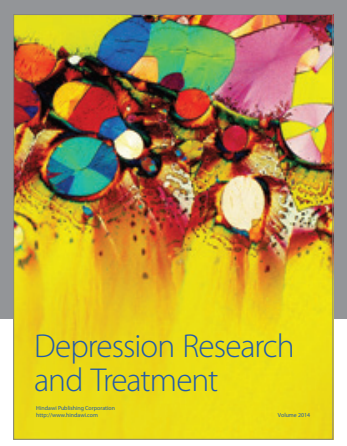
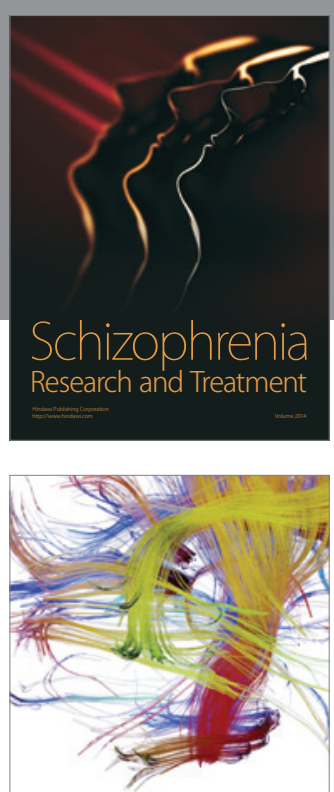

Brain Science

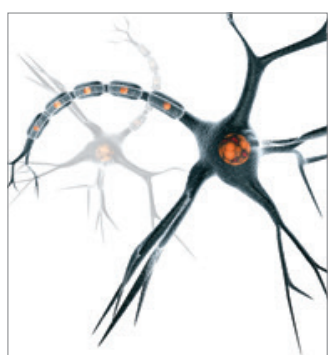

Neural Plasticity
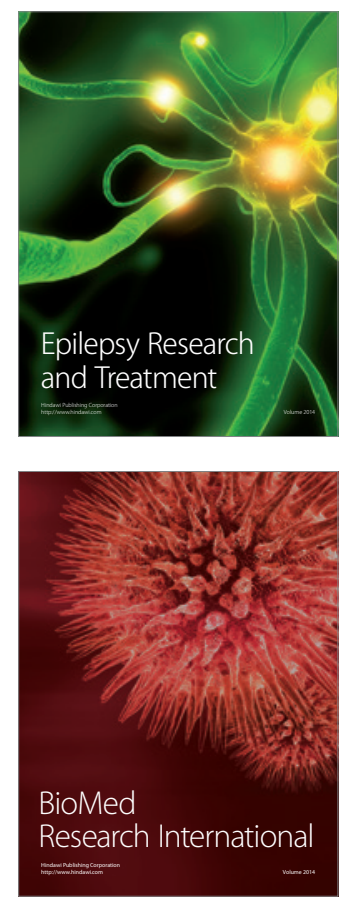

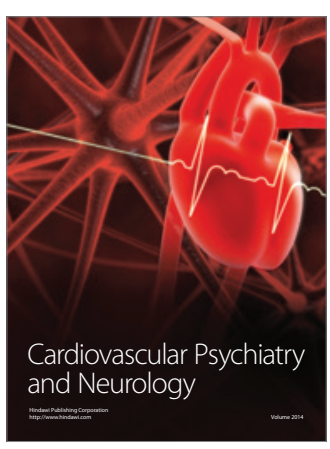

Parkinson's

Disease
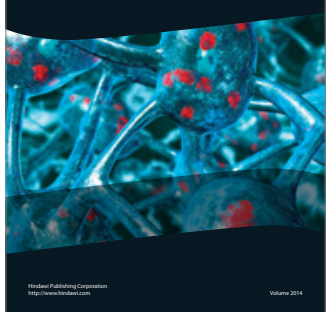